\title{
Wuhan: Britons to be evacuated as scientists estimate 44000 cases of 2019-nCOV in the city
}

\author{
Jane Parry \\ Hamilton, Canada
}

The UK government has announced plans to fly hundreds of British citizens back from Wuhan, the epicentre of the 2019-nCOV outbreak, and to quarantine them for two weeks. The move comes after British Airways suspended all flights to and from mainland China until at least 31 January. Other countries, including Australia, Japan, and the United States have also started to repatriate citizens.

Scientists at the University of Hong Kong have estimated that the likely extent of infections in the city of Wuhan is close to 44000 , based on the number of confirmed cases as of 25 January and what is known about the virus's transmissibility. "The curves have a very steep exponential shape, indicating that this epidemic is growing at quite a fast rate, and it's accelerating," said Gabriel Leung, dean of the Li Ka Shing Faculty of Medicine at the University of Hong Kong and one of the researchers, speaking at a press conference on 27 January.

The University of Hong Kong team used a basic reproductive number-the average number of secondary infections-of 2.13. "This would give us a doubling time of just shy of one week. Every six days, the epidemic case count can be expected to double in the absence of any public health interventions," said Leung.

The Chinese government suspended all transport links with the city of 11 million people and blocked the roads out of the city on 23 January, effectively putting a cordon sanitaire in place around Wuhan. In the following days it extended the quarantined zone to 15 neighbouring cities, covering a population of approximately 50 million, the Washington Post reported. ${ }^{2}$ By then, however, an estimated five million people had already left the city, mayor Zhou Xianwang said on 26 January, fanning out across the country ahead of Chinese New Year.

The modelling used by the University of Hong Kong team showed that the lockdown would probably do little to change the course of the epidemic in China. The forecast of expected infections, with or without the quarantine measures, was almost identical, which "suggests that this population quarantine may not be able to substantially change the course of this epidemic in the other major city clusters," said Leung. "If we want to change the course of those epidemic curves, then we are looking at substantial, draconian measures limiting population mobility that should be taken sooner rather than later."

Leung G Wu J. Real-time nowcast and forecast on the extent of the Wuhan CoV outbreak domestic and international spread. Media Conference 27 January 2020. Li Ka Shing Faculty of Medicine, University of Hong Kong. https://www.med.hku.hk/f/news/3549/7418/ Wuhan-coronavirus-outbreak_AN-UPDATE_20200127.pdf

2 Shih G, Lynch DJ, Denyer S, et al. Chinese coronavirus infections, death toll soar as fifth case is confirmed in US. Washington Post 26 January 2020. https://www.washingtonpost. $\mathrm{com} /$ world/asia_pacific/coronavirus-china-latest-updates/2020/01/26/4603266c-3fa8-11eaafe2-090eb37b60b1_story.html

Published by the BMJ Publishing Group Limited. For permission to use (where not already granted under a licence) please go to http://group.bmj.com/group/rights-licensing/ permissions 